Samples of bran from three varieties of wheat all freed from endosperm by treatment with dilute lactic acid gave fibre contents ranging from $12 \cdot 9$ to $14 \cdot 2$ per cent (on a 15 per cent moisture basis). Similarly, for a wheat mixture of fibre 1.95 per cent (as in Table 3 ) and assuming it contains 13-14 per cent of pure (clean) bran, calculation gives the fibre content of the pure bran as 14.4 per cent. On the basis of an average fibre of 14 per cent, column 3 in Table 3 gives the equivalent parts of 'pure' bran in each meal.

An average composition of commercial bran (pure bran and endosperm) from wheat conditioned for the milling of white flour is given below together with an analysis calculated for pure bran. This can only be a proximate analysis because the endosperm attached to commercial bran is richer in oil, protein and ash than the bulk of the endosperm. Incidentally, it would appear that the amount of endosperm attached to the commercial bran was approximately 40 per cent; with the drier milling of National wheatmeal the amount of attached endosperm will be much less and figures for the fibre content of the bran may now reach 11.5 per cent, indicating about 18 per cent of endosperm.

TABLE 4

\begin{tabular}{|l|r|r|}
\hline & Commercial bran $\%$ & Pure bran $\%$ \\
\hline Moisture & $12 \cdot 5$ & $12 \cdot 5$ \\
Oil & $4 \cdot 7$ & $8 \cdot 3$ \\
N $\times 5.7$ & $15 \cdot 0$ & $16 \cdot 8$ \\
Ash & $4 \cdot 7$ & $8 \cdot 3$ \\
Fibre & $7 \cdot 9$ & $14 \cdot 0$ \\
Non-N material & $55 \cdot 2$ & $40 \cdot 0$ \\
\hline
\end{tabular}

Comparison of Tables 2 and 3 illustrates clearly the fact that meals of nominally the same extraction may have quite different fibre contents and hence different digestibilities. The same fact has emerged even more clearly in a survey of National wheatmeal ${ }^{5}$.

Apart from the method of milling, the actual fibre content of the wheat mixture used must also be a factor. For individual wheats this may vary ${ }^{4}$ from $1 \cdot 7$ to $2 \cdot 9$, with an average for a present-day grist of about 2 per cent.

With increasing extraction the digestibility of each extraction increment will depend upon the corresponding increase in fibre content. As a matter of interest, for the meals in Table 3 the digestibilities of the fractions 85-90 per cent, 90-95 per cent and 95-100 per cent are 50, 40 and 40 per cent respectively.

All the experimental fibre values quoted in this paper were determined by Mr. R. H. Carter by a modification of the official method which he has developed for wheatmeals; each value can be reproduced to within $0 \cdot 05$. We are also indebted to Squadron Leader T. F. Macrae for allowing us to see the typescript of the paper by him and his collaborators now in the press of the Journal of Hygiene, and to Dr. C. R. Jones for much helpful criticism.

${ }^{2}$ Macrae, T. F., Bacon, J. S. D., Hutchinson, J. C. D., and MeDougall, I., Chem. and Ind., 60, No. 40, 723 (1941).

${ }^{2}$ Krebs, H. A., and Mellanby, K., Lancet, p. 3 (March 14, 1942).

${ }^{3}$ Newman, L. F., Robinson, G. W., Halnan, E. T., and Neville, H. A. D., ". Hyg., Camb., 12, 119 (1912). Rubner, M., quoted by Lusk, "Science of Nutrition" (Sammittee, 1918.

- Booth, R. G., Carter, R. H., Jones, C. R., and Moran, T., Chem. and Ind., 60, No. 52, 903 (1941).

S Staff of Research Association of British Flour-Millers, Nature, 149, 460 (1942).

\section{RADIATION FROM THE SUN}

\author{
By DR. C. E. P. BROOKS
}

A LL weather, and all life, on the earth are derived A ultimately from the sun, and knowledge of the radiation emitted from the sun may be regarded as one of the fundamental sciences. Most of our knowledge of this important subject has resulted from the work and enthusiasm of one man, Dr. C. G. Abbot, of the Astrophysical Observatory of the Smithsonian Institution, who has carried on the work for a generation in the face of many difficulties and much discouragement. The problem is indeed a difficult one, for between the sun and the earth is interposed the atmosphere, and the radiation which reaches the surface is weakened by absorption and scattering. Water vapour, dust, and to a less extent ozone are the worst enemies, and a large part of vol. 6 of the Annals of the Astrophysical Observatory is occupjed in describing the continuous attempts to overcome them during the years 1931-1940*. What might have been an even less surmountable enemy, the financial one, has been vanquished mainly with the help of Mr. John A. Roebling.

The difficulties of observation are lessened by making observations at as high a level as possible, to diminish the thickness of the atmosphere traversed by the sun's rays, and in a dry climate to minimize the loss of observations by cloud and also the weakening of the radiation by water vapour. Further, since in spite of all precautions the effect of varying weather conditions cannot be entirely eliminated, several stations must be used distributed as widely as possible in both hemispheres. For the purposes of supply the stations must also be reasonably accessible. Dr. Abbot has sent out many expeditions to test promising localities, but in the present volume the observations from only three are utilized : Montezuma, at a height of $8,895 \mathrm{ft}$. in Chile, which is the best station; Table Mountain, California $(7,500 \mathrm{ft}$.) and Mount St. Katherine, Egypt (8,500 ft.). Observations were also made for a number of years at Mount Harqua Hala in Arizona, but have not yet been worked up owing to instrumental difficulties, and at Mount Brukkaros in south-west Africa, which though almost cloudless, proved to be too dusty.

The object of the observations is to determine not only the average amount of solar radiation received at the limits of the earth's atmosphere, the so-called 'solar constant', but also its variations from day to day. Since these amount to little more than I per cent on either side of the mean (which is still set at $1.94 \mathrm{cal} . / \mathrm{cm} .{ }^{2} / \mathrm{min}$.) great precision is required both in observation and reduction. Precision in observation is obtained by the refinement of instruments. Direct measurements are made with Abbot's silverdisk pyrheliometer which serves as a permanent standard, and a modified form of Ångström's electrical pyrheliometer to give accuracy and speed in the daily observations. The loss by scattering is given by the pyranometer, which measures the brightness of the sky near the sun and hence the haziness of the air. These instruments give the total radiation falling on them, but since the radiation of different wave-lengths is differently weakened in its passage through the atmosphere, it is also necessary to obtain, with the bolometer, records of the whole

*Annals of the Astrophysical Observatory of the Smithsonian Institution. Vol. 6. By C. G. Abbot, L. B. Aldwich and W. H. Hoover. (Publication No. 3650 .) Pp. vili $+207+7$ plates. (Washington, D.C.: Smithsonian Institution. 1942.) 
spectrum from infra-red to ultra-violet. These instruments are described and illustrated in Chapter 4, which then goes on to a detailed account of the technique of reduction. The principle is very simple; the higher the sun the less the thickness of the atmosphere traversed and the greater the radiation. Hence, if the state of the atmosphere remains unchanged, a series of observations at different hours, preferably in the morning, can be extrapolated to give the radiation at zero air-mass, that is, the 'solar constant'. In the full or 'long' method computations have to be carried out for about forty different wavelengths, and even with the help of a special slide-rule they are laborious, but Dr. Abbot has been able to devise short cuts without appreciable loss of accuracy. The derivation of the 'short' method is described in detail but cannot be summarized here.

Dr. Abbot and his colleagues are continually improving their methods, and in order to maintain a homogeneous series of data, it was necessary to re-compute some of the earlier observations. This has now been done, and no less than seventy-eight pages of the report are occupied with the determinations for nearly every day from August 29, 1923, to September 29, 1939. The result is a series of "preferred" values of the solar constant, but even these are not always quite final. Some of the values show improbably large jumps from day to day, and these were checked by examination of the variations of the short-wave spectrum alone. If these gave more reasonable variations, the "preferred" values were adjusted accordingly, as a series of "improved preferred" values. Some of the resulting changes are relatively large, as much as 1 per cent, and this must to some extent impair confidence in the accuracy of the individual daily values. Dr. Abbot indeed admits as much. From a comparison of the results at three stations, he estimates the probable accidental error of a single daily value as only 0.16 per cent, but he expresses the view that only means of ten days or longer can be regarded as really reliable. Ten-day and monthly means are given from August 1920 to September 1939.

The last part of the volume is concerned with the periodogram analysis of these data. The method used is not described in detail but was apparently graphicai; short periodicities were "disclosed" by inspection and removed, disclosing longer periodicities and so on. The method is dangerous, giving rather free play to preconceived ideas of the lengths to be expected, and since all those found are integral parts of 273 months, a check by rigid Fourier analysis would have been both simple and desirable. Dr. Abbot's objection to this is that none of the periodicities is of sine form. $\mathrm{He}$ gives an illustration of the determination of three periodicities, and remarks, "We think readers may not be too favourably impressed by the comparison of the 34-month periodicity". He is quite correct in the case of one reader at least; practically the whole of the amplitude found results from the enormous range of the first of the six waves shown. His justification is that the reconstructed curve agrees closely with the original; this claim would be legitimate if all the fourteen waves were of sine form, but is doubtfully so with the complicated forms shown, each of which could be expressed as the result of several sub-waves. The lengths determined range from $8 \cdot 3$ to 273 months; recurrences at intervals of twenty-seven days associated with the sun's mean rotation period are also illustrated and there is a tantalizing reference to the temporary existence of shorter periods measured in days. No relation is found between solar radiation and sunspot numbers.

The great future importance of the study of variations in the solar constant lies in its probable application to weather forecasting. Periodicity is the most obvious method of this application, for if the solar variations are truly periodic they should be reflected, in favourable circumstances, in periodicity of weather. From the point of view of the Astrophysical Observatory, however, this is only a by-product. Dr. Abbot casually mentions that he verified the lengths of the solar periodicities of 8-68 months in meteorological data for a hundred years for three stations (with due allowance for seasonal changes) and he claims two-thirds success for long-period rainfall forecasts, but until the relations between solar and terrestrial phenomena are more fully understood forecasts are probably premature. His great service still lies in the record itself rather than in its applications.

\section{OBITUARIES}

Prof. W. H. Young, F.R.S.

William Henry Young, who died in Lausanne on July 7 when nearly eighty, was one of the mathematicians who had contributed most to the revival of English mathematics during the last fifty years.

Young was born in London on October 20, 1863 ; his family had worked in the City for some generations. His first education was at the City of London School : the headmaster, Abbott, had been a schoolfellow of his father. He went up to Cambridge, at Peterhouse, in 1881, was fourth Wrangler in 1884, and a fellow of his College from 1886 until 1892 ; in 1939 he was made an honorary fellow. In his early graduate years he did a great deal of teaching, both as a private coach (as was usual with Cambridge mathematicians then) and more officially as a lecturer at Girton. In 1896 he married Grace Chisholm, who had been one of his pupils and was also a fine mathematician. He was the first Hardinge professor of mathematics in Celleutta from 1913 until 1916, professor of the philosophy and history of mathematics in Liverpool from 1913 until 1919, and professor of pure mathematics in Aberystwyth from 1919 until 1923; but the first two of these chairs were rather 'occasional' appointments, and it is something of a scandal that he should never have occupied a regular position really worthy of a mathematician of his rank.

Young became a fellow of the Royal Society in 1907, and was Sylvester Medallist in 1928; was de Morgan Medallist of the London Mathematical Society in 1917, and president from 1922 until 1924; and president of that rather unhappy body, the International Union of Mathematicians, from 1929 until 1936. He leaves his wife and five children, two of whom are also well-known mathematicians.

Young wrote three books (two in collaboration with his wife) and about two hundred papers, all crowded into a little more than twenty years of his life; he was over forty when his first important papers were published. $\mathrm{He}$ belonged to the generation of mathematicians which includes Burnside, A. C. Dixon, Forsyth, Hubson, Love, and MacMahon, and was fully the equal of any of them in originality and power; but all of them had established their 